\title{
Evidence and Explanation in Cicero's On Divination
}

\begin{abstract}
In this paper, I examine Cicero's oft-neglected De Divinatione, a dialogue investigating the legitimacy of the practice of divination. First, I offer a novel analysis of the main arguments for divination given by Quintus, highlighting the fact that he employs two logically distinct argument forms. Next, I turn to the first of the main arguments against divination given by Marcus. Here I show, with the help of modern probabilistic tools, that Marcus' skeptical response is far from the decisive, proto-naturalistic assault on superstition that it is sometimes portrayed to be. Then, I offer an extended analysis of the second of the main arguments against divination given by Marcus. Inspired by Marcus' second main argument, I formulate, explicate, and defend a substantive principle of scientific methodology that I call the "Ciceronian Causal-Nomological Requirement" (CCR). Roughly, this principle states that causal knowledge is essential for relying on correlations in predictive inference. Although I go on to argue that Marcus' application of the CCR in his debate with Quintus is dialectically inadequate, I conclude that De Divinatione deserves its place in Cicero's philosophical corpus, and that ultimately, its significance for the history and philosophy of science ought to be recognized.
\end{abstract}




\section{Introduction}

Composed between 45-44 BCE, De Divinatione ("On Divination") is a dialogue featuring both the author, Marcus Tullius Cicero (106-43 BCE), and his brother Quintus as characters examining the legitimacy of the practice of divination. De Divinatione is divided into two books, each of which contains its own prologue. In the first book, Quintus attempts to establish the rationality of divination in various ways, most notably by appealing to a plethora of exempla-examples of divination, both Roman and non-Roman, which for Quintus are unassailable. In the second book, Marcus ${ }^{1}$ attempts to undermine his brother's arguments with a mix of philosophical argument and the sort of rhetorical vituperatio ("invective") characteristic of Roman oratory.

Traditionally, it was thought that Cicero the author meant to endorse the critique of divination given by Marcus in Book II, and that thus we ought to read De Divinatione "as a vigorous rationalistic protest" (Pease 1920:13). On this view, Cicero's intention was to show that "augury had no divinatory value and was established solely for reason of State" (Linderski 1982: 28). More recent scholarship, most notably Beard (1986), Schofield (1986), and Krostenko (2000) has questioned the traditional view according to which we should attribute to Cicero a straightforward religious skepticism. For instance, Beard (1986) emphasizes that De Divinatione is not written as a one-sided treatise directed wholly against divination; rather, Cicero deliberately has Quintus give arguments for divination in Book I, and "in the traditions of the Academic school of philosophy, the reader is left to make up his own mind on the most convincing case" (Beard 1986: 35). Although much scholarly work exists attempting to reconstruct the real intentions of Cicero in drafting the dialogue, few have taken the time to look closely at the actual philosophical content of the text. ${ }^{2}$ One reason for this neglect is that De Divinatione has the reputation of being "the least philosophical of all Cicero's philosophical dialogues" (Wardle 2006: v). As Schofield (1986: 50) claims, De Divinatione "takes a lot of getting through for philosophers", being "leisurely and expansive" and lacking the "subtleties of philosophical argument".

As I aim to show, however, this negative view of De Divinatione does not withstand critical scrutiny. The remainder of the article is organized as follows. First, I will offer a novel analysis of the main arguments for divination given by Quintus, highlighting the fact that he employs two logically distinct argument forms. Next, I will turn to the first of the main arguments against divination given

\footnotetext{
${ }^{1}$ Here, I follow Beard (1986) in using "Cicero" to refer to the author of the dialogue and "Marcus" to refer to the character in the dialogue.

${ }^{2}$ Two notable exceptions are Woolf (2015) and Denyer (1985).
} 
by Marcus. Here I will show, with the help of modern probabilistic tools, that Marcus' skeptical response is far from the decisive, proto-naturalistic assault on superstition that it is sometimes portrayed to be. Rather, as I will show, Marcus' counter-argument relies crucially on certain purely theological premises. Then, I will offer an extended analysis of the second of the main arguments against divination given by Marcus. Inspired by Marcus' second main argument, I formulate, explicate, and defend a substantive principle of scientific methodology that I call the "Ciceronian Causal-Nomological Requirement" (CCR). Roughly, this principle states that causal knowledge is essential for relying on correlations in predictive inference. Although I will argue that Marcus' application of the CCR in his debate with Quintus is dialectically inadequate, I'll conclude that De Divinatione deserves its place in Cicero's philosophical corpus, and that ultimately, its significance for the history and philosophy of science ought to be recognized.

\section{Quintus' Empirical Case for Divination in Book I}

In the prologue of Book I, Cicero begins the text by defining divination as the "presentiment and knowledge of future things" $(1.1)^{3}$. Shortly thereafter, Cicero has Quintus clarify for us that the "future things" of which divination supposedly gives one knowledge are those things "thought to occur by chance" (1.9). This qualification is needed to help distinguish divination from mere practical wisdom or theoretical science. A clever and experienced general may be able to confidently predict the outcome of some tactical maneuver. So too, an expert astronomer will be able to predict, with virtual certainty, the date of the next solar eclipse. But such abilities ought not to count as divination, since they are typically thought to involve grasping certain natural regularities and relations of cause and effect. Because of the existence of these natural regularities, in the domains of theoretical science and practical wisdom, the events being predicted are not "thought to occur by chance." Thus, such endeavors won't count as divination.

We can further distinguish between science/practical wisdom by noting that Quintus explicitly endorses the following biconditional: the practice of divination is legitimate if and only if the gods exist (1.9). In endorsing this claim, Quintus strongly suggests that divination, in some important sense, "depends on" the gods in a way that theoretical science or practical wisdom does not. Indeed, immediately after Quintus approves the biconditional, Marcus demurs that "the future can be announced naturally without the involvement of a god' (1.10; emphasis mine). In addition, later in

\footnotetext{
${ }^{3}$ All references to Cicero are from De Divinatione unless otherwise noted. I rely on the new Wardle (2006) translation for Book I, and the older Loeb Classical Library edition for Book II.
} 
Book II, Marcus cites a definition of divination due to Chrysippus, according to which divination is “The power to see, understand, and explain premonitory signs given to men by the gods" (2.130).

Although further problems might remain for neatly distinguishing theoretical science and practical wisdom from divination, we can get a sufficient grasp of the concept for the present purposes by reference to paradigmatic cases, e.g. astrology, haruspicy (i.e. reading entrails), interpreting divinely inspired dreams, interpreting the feeding pattern of sacred birds, etc. Unlike the science of astronomy or the practical wisdom of generalship, genuine divination acts as a kind of bridge between the human world and the divine. Such practices allow humans to augment their predictive capacities with the ability to gain knowledge of events thought to be result of chance.

The dramatic setting of the dialogue that ensues consists of a conversation at his Tusculan villa between Marcus and his brother Quintus (1.8). Disappointed that De Natura Deorum failed to discuss divination, Quintus proposes a joint examination of the topic. Helpfully, Quintus divides divination into two classes, "the one involving a technique, the other involving nature" (1.11). The former class, which he calls "artificial" (artificiosa) divination, includes astrology, interpreting the flights of birds, haruspicy, etc. These all require some training or expertise, without which one will not be able to understand what such natural phenomena really signify. The other class involving nature, which he calls "natural" (naturale) divination, includes visions of the future via some dream or through some other frenzied state. This kind of divination does not require expertise because it involves a more straightforward perception of the future.

Quintus is forthright about his position: divination, both natural and artificial, is legitimate. He relies on several arguments for this conclusion, some of which are more promising than others. At times, Quintus seems to make a simple-minded appeal to popularity/authority_ “'I...will not be led to hold that on the subject of entrails the whole of Etruria is out of its mind" (1.35)—or appeal to tradition- "So do we despise these signs given by the gods and sanctioned by our ancestors?" (1.102). However, such arguments are most charitably viewed as part of Quintus's main argument, namely that history has afforded us countless "clear and obvious" cases of humans successfully divining the future (1.10). The argument that Quintus attempts to make is thus primarily an empirical one.

What follows then, and what takes up the majority of Book I, is a "messy welter of allegedly divinatory experiences" (Schofield 1986: 52), where Quintus alternates between Greek and Roman examples. Indeed, one might suspect that Quintus' strategy in Book I is to overwhelm the reader with examples so as to compel belief in his central claim by brute force. Since Quintus only intends 
to defend the general claim that divination is possible, it may not matter much if some of his examples are dubious, so long as at least one is too implausible to explain away as something other than genuine divination (Cf. 1.71; 1.124). A sampling of the exempla cited by Quintus can be found in the table below:

\section{Table 1}

\begin{tabular}{|c|c|c|}
\hline Location in Text & Natural Sign & Foretold Outcomes \\
\hline 1.16 & $\begin{array}{l}\text { Lightning hit the statue of Summanus on } \\
\text { top of the temple of Jupiter. }\end{array}$ & $\begin{array}{l}\text { The missing head was successfully } \\
\text { predicted to be in the Tiber. }\end{array}$ \\
\hline 1.72 & A certain number of sparrows is observed & $\begin{array}{l}\text { The Trojan War was successfully } \\
\text { predicted to last the same number of } \\
\text { years }\end{array}$ \\
\hline 1.73 & $\begin{array}{l}\text { The horse of Dionysius disappeared in a } \\
\text { whirlpool and reemerged later with a swarm } \\
\text { of bees on its mane. }\end{array}$ & $\begin{array}{l}\text { It was successfully predicted that } \\
\text { Dionysius would soon begin his reign. }\end{array}$ \\
\hline 1.77 & $\begin{array}{l}\text { Flamininus fell on his horse before the } \\
\text { statue of Jupiter; the sacred chickens would } \\
\text { not eat; the standard bearer could not move; } \\
\text { earthquakes occurred. }\end{array}$ & $\begin{array}{l}\text { The Roman army was annihilated by } \\
\text { Hannibal at the Battle of Lake } \\
\text { Trasimene. }\end{array}$ \\
\hline 1.78 & $\begin{array}{l}\text { Ants piled wheat in Midas's mouth when he } \\
\text { was a child. }\end{array}$ & $\begin{array}{l}\text { He was successfully predicted to become } \\
\text { rich. }\end{array}$ \\
\hline 1.85 & $\begin{array}{l}\text { A split lung is observed in a sacrificial } \\
\text { animal. }\end{array}$ & $\begin{array}{l}\text { Disaster will happen unless the } \\
\text { undertaking is postponed. }\end{array}$ \\
\hline 1.85 & $\begin{array}{l}\text { The conjunction of Jupiter or Venus with } \\
\text { the Moon is observed. }\end{array}$ & A child's birth is favorable. \\
\hline 1.85 & $\begin{array}{l}\text { The conjunction of Mars and Saturn is } \\
\text { observed. }\end{array}$ & nfavorable. \\
\hline 1.119 & $\begin{array}{l}\text { There was no heart in the bull sacrificed by } \\
\text { Caesar. }\end{array}$ & $\begin{array}{l}\text { It was successfully predicted that Caesar } \\
\text { would die. }\end{array}$ \\
\hline 1. 121 & $\begin{array}{l}\text { A woman dreams that she gave birth to a } \\
\text { lion. }\end{array}$ & $\begin{array}{l}\text { The country in which this occurred is } \\
\text { overcome by foreign nations. }\end{array}$ \\
\hline
\end{tabular}

In addition to citing a wealth of colorful examples, Quintus' argument also relies on empirical generalizations concerning the reliability of established forms of divination, such as astrology, haruspicy, and the various auspicia (e.g. ex caelo and ex avibus). According to Quintus, throughout history, expert diviners have amassed a system of correlations between natural signs (e.g. lightning bolts, chicken feeding patterns, etc.) and the future outcomes they signify (e.g. a military disaster, fame and glory, etc.). Consider the following passage, which is perhaps the most forceful and forthright expression of Quintus' main argument (1.109):

"For what is known in advance from entrails, lightning, portents, and the stars is recorded as a result of observation over a long period (observatione diuturna). In all these areas the great length of time produces an extraordinary science through prolonged observation. This can exist even without the intervention and inspiration of the gods, since through frequent 
experience it is clearly known what is the result of each sign and what precedes any given event."

The empirical evidence for these correlations is, according to Quintus, undeniable (1.26; 1.67). Over time, observational evidence has allowed for a systematic science of divination, which links various signs to what they signify. While far from perfect, according to Quintus, the correlations that practitioners of divination employ are so strong that they can be used for prediction.

\section{Quintus' Two Logically Distinct Argument Forms}

While Quintus' main argument seems rather straightforward, there is one feature of his empirical case for divination that is easy to neglect. That is, Quintus relies on two logically distinct argument forms, which we should make explicit. The argument form suggested by the claims about stable correlations between sign and signified appears to be what is often called "enumerative induction". Given some predicates $F$ and $G$, and some object $a$, then according to a standard account of enumerative induction, the following is a cogent form of inference:

(1) The overwhelming majority of Fs are Gs.

(2) $a$ is an $F$.

(3) Therefore, probably, $a$ is a $G$.

The commitment to this form of argument is most clearly expressed when Quintus writes, in defense of established forms of divination, that "identical signs have preceded identical outcomes in identical ways on a number of occasions almost beyond counting” (1.26).

So, for instance, take some of the astrological claims that Quintus mentions, which are cited in Table 1. According to the astrological tradition, the conjunction of Jupiter or Venus with the Moon during the birth of a child is, generally, favorable for the child. Applying the above argument form to this case, we are left with the following reconstruction of an argument about the life prospects of an arbitrary child—let's call that arbitrary child "Tullia":

(i) Most children born under the conjunction of Jupiter or Venus with the Moon were predisposed to lead successful lives.

(ii) Tullia was born under the conjunction of Jupiter with the Moon.

(iii) Therefore, probably, Tullia is predisposed to live a good life.

In the passages in which Quintus claims that expert diviners and augurs have amassed a wealth of knowledge about which astrological signs are correlated with which outcomes, the above argument form is plausibly what appears to be in the background. 
One might wonder why it is that the inference above is inductive in form, if as Quintus claims, "identical signs have preceded identical outcomes", and moreover, if as Quintus claims later, "in the beginning, the universe was so created that certain results would be preceded by certain signs" (1.118). If, in accordance with the Stoic doctrine of determinism, which Quintus endorses (1.127), the universe contains an orderly system of sign and signified, one might think that the inference should instead to be deductive in form, e.g.:

(1) All Fs are Gs

(2) $\mathrm{x}$ is an $\mathrm{F}$

(3) Therefore, $x$ is a $G$

Any inconsistency here is, however, merely apparent. The argument form is best construed inductively, not because the relationship between sign and signified in irreducibly probabilistic, but because human beings are fallible. Although Quintus claims that divination succeeds often but not always $(1.24 ; 1.25 ; 1.35 ; 1.60 ; 1.67 ; 1.71 ; 1.126)$, the reason for this is not that reality is indeterministic, rather predictive failures result when "some sign is given indefinitely but it is taken as certain, or some sign can remain unobserved, either the relevant sign or another sign contrary to it" (1.124). Granted, if it were possible for some diviner to take a god's-eye-view of the universe-a scenario Quintus considers (1.127) — it would then make sense to regard the inference from sign to outcome as deductive. But given human cognitive limitations, at most diviners may aspire only to inductive arguments for their conclusions. For Quintus, however, this is not a serious problem, for divination "errs perhaps occasionally, but nonetheless on most occasions directs us to the truth (1.25).

Crucially, however, the above analysis does not work for all of Quintus' examples. The astrological case cited about refers to a repeatable event-type, whereas many of the examples cited in Table 1 consist in singular, individual event-tokens. In many cases, Quintus does not explicitly claim that this event is a token instance that we can, at least at present, subsume under some repeatable regularity. Indeed, there is some direct textual evidence that Quintus divides the class of artificial divination into to further types to account for this fact. As Quintus tells us: "Some of them [i.e. artificial divination] depend on records and lore, as the books of the Etruscans on haruspicy, lightning, and rituals show, and also your books on augury. Others are explained by unprepared conjectures in accordance with the situation" (1.72; emphasis mine). According to Quintus, while we can subsume some signs under established regularities, e.g. the astrological example, in other cases, while there may indeed be some regularity out there waiting to be discovered, such a regularity is at least unknown to us. Nevertheless, successful divination remains possible even in the absence of some 
established regularity. As Wardle (2006: 282-3) notes, in these singular, individual cases, "the auspice or portent was without parallel and so has to be interpreted by analogy with known signs thus taking account of the circumstances and necessitating the employment of rationality." Shortly after introducing this further distinction and discussing some examples, Quintus asks rhetorically, "What, then, are we waiting for? Till the immortal gods converse with us when we're in the Forum, in the street, or at home?" (1.79). Clearly, Quintus suggests that these singular occurrences should be so compelling on their own, to convince the reader that divination is legitimate.

In my view, a plausible way to formalize Quintus' use of remarkable, individual cases, especially given his claim that these cases are "explained by unprepared conjectures in accordance with the situation", is to appeal to an argument form that Harman (1965) dubbed "inference to the best explanation" (IBE). ${ }^{4}$ Also discussed under the heading of "abduction" or "explanatory reasoning", IBE is an inference method that manifests the taking of an "explanatory detour" (Lipton 2004: 65). A hypothesis $H$ is upheld as rationally justified by showing how well $H$ would, if true, explain some set of facts. That $\mathrm{H}$ would explain these facts better than its competitors is taken to ground our justification for believing $\mathrm{H}$. Often, IBE is formalized as a four-step argument pattern (e.g. Psillos 2002; Lycan 1988), such as:

(1) $\mathrm{F}$ is some fact or collection of facts

(2) Hypothesis $\mathrm{H}_{1}$, if true, would explain $\mathrm{F}$

(3) $\quad \mathrm{H}_{1}$ is a better explanation of $\mathrm{F}$ than its competitors $\mathrm{H}_{2}, \mathrm{H}_{3}, \ldots \mathrm{H}_{\mathrm{n}}$

(4) Therefore, probably, $\mathrm{H}_{1}$ is true

According to Douven (2011), our use of IBE in everyday life is "so routine and automatic that it easily goes unnoticed". Moreover, there is a long list of prominent episodes from the history of science in which it is claimed that IBE was the form of reasoning at play (Thagard 1978).

Now with this conception of IBE in mind, and turning our attention to the Flamininus example, we can plausibly interpret Quintus as reasoning as follows:

(i) Before the disastrous defeat in the Battle of Lake Trasimene, Flamininus fell on his horse before the statue of Jupiter; the sacred chickens would not eat; the standard bearer could not move; earthquakes and other natural disasters were observed. This conjunction of events requires an explanation.

(ii) That this set of events was a divine sign indicating the battle was destined to be lost if undertaken would, if true, explain the conjunction of events.

(iii) Such an explanation in terms of divination is better than rival explanations.

\footnotetext{
${ }^{4}$ Woolf (2015: 71-2) gestures at the fact that for Quintus singular cases appear, by themselves, probative, but Woolf does not explicitly invoke IBE to capture this feature of Quintus' argument.
} 
(iv) Thus, probably, the set of events preceding the lost battle were a divine sign indicating that the battle was destined to be lost if undertaken.

What are the other possible explanations besides the one favored by Quintus? Shortly before relating the story of Flamininus' loss to Hannibal, Quintus claims that we will have established that divination is possible "if there is one instance of something being foretold in such a way that it evidently could not have happened by chance" (1.71). Plausibly then, the alternative explanation against which the divination explanation competes is one that says the conjunction of these events was due to chance. While we could imagine other logically possible explanations, these are clearly not in the space of cognitively available alternatives. For Quintus, these striking, one-off cases of apparent divination are either compelling evidence of the reality of divination or ought to be dismissed as a chance confluence of events. No other live options remain.

\section{Marcus' First Skeptical Response: The Strategy of Alternative Explanations}

In Book II, Marcus employs several arguments against Quintus. The most straightforward objection to Quintus' main argument for divination is that the historical track record of haruspices, astrologers, and other diviners simply is not what Quintus claims. According to Quintus, divination has proved so successful in the past that, despite the occasional mistake, we are justified in employing it for future inferential purposes. However, according to Marcus, this account of the past success of divination wholly misrepresents its reliability. As Marcus objects (2.53):

"Why need I give instances-and, in fact, I could give countless ones-where the prophecies of soothsayers either were without result or the issue was directly the reverse of the prophecy?... Still, you are aware that the result was nearly always contrary to the prophecy."

With historical hindsight, it's easy to be sympathetic with Marcus' incredulous rebuke: "Now can anybody be induced to believe that the things said to be predicted by means of entrails were learned by the soothsayers through 'long continued observation'?" (2.26). Although the modern reader is likely in agreement with Marcus here, this judgment is driven not by any direct inspection of the success rate of divination, but rather owes to more general background commitments. These background commitments make the idea of relying on divination a non-starter. ${ }^{5}$ But of course, any sincere assessment of Quintus' main argument depends on having a detailed record of the success rate of the various practices of divination—something which is lacking here.

${ }^{5}$ Lehoux (2012, Ch. 6) makes a similar point with respect to the contemporary rejection of the ancient belief that garlic negates the attractive powers of a magnet. 
We must remember, though, that Quintus appears to offer two logically distinct arguments for the legitimacy of divination, only one of which exploits the stability of observed associations between sign and signified. Consequently, even if we grant Marcus his skepticism about observed frequencies, this won't undermine the arguments that Quintus gives which appeal to singular, individual cases. Instead, Marcus' objection in these singular cases involves, what I'll call the "strategy of alternative explanations".

Consider the Flamininus case again. As I suggested, the series of striking events put forward by Quintus are naturally cast in the mold of IBE. To block the explanatory inference that Quintus attempts to make, Marcus offers alternative explanations for some of the anomalous phenomena, ones intended to be at least as good as the divinatory explanation. Such explanations typically appeal to mundane natural causes rather than divine forewarning. For example, Marcus suggests, rather than being a divine sign that the Roman army ought to halt its advance, perhaps the inability for the standard-bearer to lift the standard resulted from his having "planted it stoutly and pulled it up timidly" (2.67). While Marcus offers only one "debunking" explanation of one of the signs in the Flamininus case, presumably, other non-divinatory, alternative explanations for the other signs could be constructed. We find similar alternative explanations of alleged, divine signs throughout Book II (e.g. $2.58 ; 2.68 ; 2.140)$. For other cases, such as the events allegedly portending the Spartan defeat in the Battle of Leuctra, Marcus suggests that chance could be the explanation, rather than divine agency. If Marcus' is right that such explanations are at least as good as the divinatory explanations, then this fact would undermine the rational support for Quintus' view.

\section{A Formal Reconstruction of the Strategy of Alternative Explanations}

Let's take a closer look at the strategy of alternative explanations. ${ }^{6}$ Consider, for instance, Marcus' alternative explanation for the recalcitrant standard. For convenience, let STANDARD be

\footnotetext{
${ }^{6}$ Here and throughout, I will take it as unproblematic to appeal to the modern probabilistic machinery to better understand the arguments in the text. Now, one might object that before the foundational work of $16^{\text {th }}$ and $17^{\text {th }}$ century mathematicians the concept of probability simply did not exist. This is the thesis propounded most famously by Hacking (1975). However, Hacking's central thesis regarding the emergence of probability has been, I take it, roundly refuted. See, for example, Laudan (1978), Garber and Zabell (1979), and Brown (1987). Both aspects of the modern concept of probability that Hacking finds essential, namely the concept of warranted degree of belief and the concept of stable frequencies, can be found in the writings of pre-modern thinkers. As Garber and Zabell point out (1979:45), we can find traces of both concepts in the writings of Cicero, who, importantly, was an adherent of the school of Academic Skepticism which endorsed a probabilistic epistemology. Indeed, the connection between the modern "subjective" view of probability and the Academic Skeptics has not escaped the notice of contemporary Bayesians (Jeffrey 1984). Thus, we should understand probability here in the Bayesian way, as expressing and formalizing the concept of
} 
"the standard stood still", let BEARER be "the standard-bearer planted the standard stoutly and pulled it timidly", and let DIVINE be "the gods wanted to warn Flaminius to not engage Hannibal". Then, we might interpret Marcus as endorsing the following probabilistic equality:

$\operatorname{Pr}($ STANDARD $\mid$ BEARER $)=\operatorname{Pr}($ STANDARD $\mid$ DIVINE $)$

What this claim signifies is that the alternative explanation offered by Marcus is just as good as the one offered by Quintus, in the sense that both hypotheses, BEARER and DIVINE, if true, would confer upon the observed sign the same probability. That is, both have the same "likelihood". For both BEARER and DIVINE, if either is true then we should expect STANDARD to also be true. For this reason, neither BEARER nor DIVINE is preferable for accounting for STANDARD. ${ }^{7}$

In the Flaminius case, Marcus' aims appear to be modest, suggesting that BEARER is "perhaps" the explanation for STANDARD. At least, Quintus has not ruled out this rival explanation. This modesty comports with the skeptical methodology endorsed by the Academic school, to which Marcus (along with Cicero the author) adheres. As Marcus informs us at the outset of Book II, "I must do so with great diffidence and with many misgivings, and in such a way as to affirm nothing and question everything" (2.8).

However, despite Marcus' intention to "affirm nothing and question anything", he sometimes seems to affirm some non-divinatory explanation over the divinatory explanation defended by Quintus, suggesting that these are better explanations and not merely explanations that are equally good. Strikingly, Marcus writes: "Not to be too verbose, all portents have one and the same explanation and it is this: whatever comes into existence, of whatever kind, must needs find its cause in nature" (2.60). In addition, Marcus often seems to regard particular, non-divinatory explanations as better than their divinatory alternatives:

"his [i.e. Gracchus's] death was caused by some very serious illness and not by the release of the snake" (2.62)

"In my view of the case Deiotarus employed the auspices of virtue" (2.78)

"That appears to me to have been the work of thieves rather than of gods" (2.68)

"it is evident that one's birth is more affected by local environment than by the condition of the moon" (2.97)

subjective "degrees of belief", a concept Cicero appears to have had. Of course, we should not attribute the modern form of Bayesianism to Cicero, but given his "instinctive feeling about probability (David 1969, p. 24), and other facts about Cicero's philosophical background, the invocation of the probability calculus does, I believe, help us make more precise and better evaluate the arguments in the text.

${ }^{7}$ As will become clear below, if Marcus is committed to saying that BEARER and DIVINE are equally good explanations, then he must also be committed to saying that the two have equal prior probabilities. 
"Chrysippus filled a whole volume with your oracles; these some, as I think, were false; some came true by chance" (2.115)

"in the time of my banishment Marius was often in my mind... and this I think is the reason why I dreamed about him." (2.140)

Although as an Academic skeptic Marcus won't dogmatically believe one view over another, as he reminds us, "it is characteristic of the Academy...to approve those which seem to approach nearest to the truth" (2.150). Thus, it appears in keeping with Marcus' skepticism to regard some nondivinatory explanations as better than Quintus' divinatory explanations. Although Marcus is more diffident about the explanation of the alleged portents associated with the defeat of Flaminius, let's suppose for the sake of simplicity that Marcus takes BEARER to be preferable to DIVINE, and not merely equally good. How might we analyze this stronger view?

The sense in which non-divinatory explanations might be preferable is that, overall, they have a higher probability given the evidence than divinatory explanations, even if their likelihoods are equivalent. In assessing an explanatory hypothesis, we don't only care about how the explanans relates to the explanandum; we care also about the intrinsic quality of the explanans. As proponents of embedding IBE within the Bayesian framework have suggested (Okasha 2000; Lipton 2004; Weisberg 2009; Poston 2014), such intrinsic features of an explanation, such as its simplicity or fit with background knowledge, are reflected in the prior probability of the explanation.

Now then, consider the following theorem of the probability calculus, where $\mathrm{H}_{1}$ is some hypothesis, $\mathrm{H}_{2}$ some rival hypothesis, and $\mathrm{E}$ some evidence:

(Theorem 1) $\operatorname{Pr}\left(\mathrm{H}_{1} \mid \mathrm{E}\right)>\operatorname{Pr}\left(\mathrm{H}_{2} \mid \mathrm{E}\right)$ if and only if $\operatorname{Pr}\left(\mathrm{H}_{1}\right) \operatorname{Pr}\left(\mathrm{E} \mid \mathrm{H}_{1}\right)>\operatorname{Pr}\left(\mathrm{H}_{2}\right) \operatorname{Pr}\left(\mathrm{E} \mid \mathrm{H}_{2}\right)$

According to Theorem 1, the "posterior probability" of $\mathrm{H}_{1}$, i.e. $\operatorname{Pr}\left(\mathrm{H}_{1} \mid \mathrm{E}\right)$, is greater than the posterior probability of $\mathrm{H}_{2}$ if and only if the product of the "prior probability", i.e. $\operatorname{Pr}(\mathrm{H})$, and the likelihood of $\mathrm{H}_{1}$, i.e. $\operatorname{Pr}\left(\mathrm{E} \mid \mathrm{H}_{1}\right)$, is greater than the product of the prior and likelihood of $\mathrm{H}_{2}$.

If we apply Theorem 1 to the contest between DIVINE and BEARER, we have the following biconditional:

$\operatorname{Pr}($ DIVINE $\mid$ STANDARD) $>\operatorname{Pr}($ BEARER $\mid$ STANDARD) if and only if $\operatorname{Pr}($ DIVINE) $\operatorname{Pr}($ STANDARD $\mid$ DIVINE) > Pr(BEARER)Pr(STANDARD |BEARER)

Notice that Theorem 1 entails that if $\operatorname{Pr}\left(\mathrm{E} \mid \mathrm{H}_{1}\right)=\operatorname{Pr}\left(\mathrm{E} \mid \mathrm{H}_{2}\right)$, then $\operatorname{Pr}\left(\mathrm{H}_{1} \mid \mathrm{E}\right)>\operatorname{Pr}\left(\mathrm{H}_{2} \mid \mathrm{E}\right)$ just in case $\operatorname{Pr}\left(\mathrm{H}_{1}\right)>\operatorname{Pr}\left(\mathrm{H}_{2}\right)$. Since it is plausible that the respective likelihoods of DIVINE and BEARER are equivalent, i.e., both explanations would, if true, make STANDARD a matter of course, it seems that the contest between DIVINE and BEARER comes down to prior probabilities. 
Several remarks made by Marcus suggest that he regards non-divinatory explanations, such as BEARER, as having a higher prior probability than the divinatory explanations offered by Quintus. The reason that the divinatory explanations, such as DIVINE, are antecedently improbable, according to Marcus, is that such explanations require ascribing attitudes, dispositions, and goals to the gods that they are unlikely to possess, in virtue of being gods. Consider the following passages, in which Marcus relies upon substantive background beliefs about the nature of the gods ${ }^{8}$ :

"Is it not strange fickleness in the gods to threaten disaster in the first set of entrails and to promise a blessing in the next?" (DD, 2.38; emphasis mine)

"It is passing strange, if Jupiter warns us by means of thunderbolts, that he sends so many to no purpose!” (2.44)

"In the first place, why do immortal gods see fit to give us warning which we can't understand without the aid of interpreters?...If these signs you speak of are to be considered as sent by the gods, why were they so obscure? (2.54-5)

"Do you really believe that Jupiter would have employed chickens to convey such a message to so great a state?" (2.56)

As these passages suggest, Marcus regards the explanations offered by Quintus as antecedently improbable, even if they would account for the observed phenomena, because such explanations attribute actions to the gods that are inconsistent with their dignity, nobility, and divine status. The divinatory explanations paint a vulgar picture of capricious gods, using lowly signs such as chickens and errant thunderbolts to send obscure messages to human beings. Thus, we should believe that the prior probability of divinatory explanations is much lower than rival explanations.

Returning to the contest between DIVINE and BEARER, and assuming that $\operatorname{Pr}($ STANDARD $\mid$ BEARER $)=\operatorname{Pr}($ STANDARD $\mid$ DIVINE), then if $\operatorname{Pr}($ BEARER $)>\operatorname{Pr}(\mathrm{DIVINE})$, it follows by Theorem 1 that $\operatorname{Pr}($ BEARER $\mid$ STANDARD) $>\operatorname{Pr}($ DIVINE |STANDARD). Even if such divinatory explanations would, if true, explain the observed phenomena, nevertheless, according to the stronger view that Marcus sometimes seems to endorse, we ought to prefer non-divinatory explanations. The likelihoods of such explanations are comparable or equivalent to those of the divinatory explanations, and, crucially, non-divinatory explanations have higher prior probabilities. As a result, non-divinatory explanations have higher posterior probabilities. ${ }^{?}$

\footnotetext{
${ }^{8}$ See also the lengthy passage at 1.129 in which considerations of probability are directly invoked.

${ }^{9}$ It is worth noting that the appeal to theoretical considerations is not the only way in which a low prior probability for DIVINE might be justified. It is a commonplace that prior probabilities ought to be determined by frequency data (e.g. Roche and Sober 2013). With this idea in mind, if the frequency of divine
} 
Now, recall that Marcus' strategy of alternative explanation sometimes manifests itself as the claim that "chance" is a preferable explanation to those that are put forward by Quintus. Interestingly, the appeal to chance calls for a slightly different analysis. Consider the following appeal to chance that Marcus makes (2.121):

"Nothing is so uncertain as a cast of dice and yet there is no one who plays often who does not sometimes make a Venus-throw and occasionally twice or thrice in succession. Then are we, like fools, to prefer to say that it happened by the direction of Venus rather than by chance?"

In the game of dice to which Marcus refers, the probability of a "Venus throw" is, assuming the equi-probability ${ }^{10}$ of all four faces showing up on a single toss, .09375 . Thus, the probability of three Venus throws in a row is $.09375^{\wedge} 3$, which is equal to 0.0008239746 , or about a $.08 \%$ chance.

With this in mind, let CHANCE be "the toss of the dice is a genuine chance process", let THREE be "three Venus throws show up in a row", and finally let VENUS be the divinatory explanation according to which "the goddess Venus favors the thrower of the dice". If we know that Venus favors the gambler, then the following likelihood inequality obtains:

$\operatorname{Pr}($ THREE $\mid$ VENUS $)>\operatorname{Pr}($ THREE $\mid$ CHANCE $)$

The crucial difference in this case, which makes it importantly distinct from the contest between DIVINE and BEARER, is that Marcus won't be able to get away with saying that the likelihoods of VENUS and CHANCE are equivalent. After all, Venus surely has the power to influence the dice, and if she favors the present gambler, she will have the power to make THREE more probable than it would be conditional on CHANCE.

Now, Marcus suggests here that the chance explanation is preferable to the divinatory explanations offered by Quintus. However, it is crucial to note that this can be true only if it is the case that $\operatorname{Pr}(\mathrm{CHANCE})>\operatorname{Pr}(\mathrm{VENUS})$ and, moreover, only if the arithmetical difference between the two explanations is sufficiently high so as to compensate for the fact that $\operatorname{Pr}($ THREE $\mid$ VENUS $)>\operatorname{Pr}($ THREE $\mid$ CHANCE). If Marcus is committed to the conclusion that $\operatorname{Pr}($ CHANCE $\mid$ THREE $)>\operatorname{Pr}($ VENUS $\mid$ THREE $)$, then he must be committed to the further claim that the antecedent probability of CHANCE is much higher than that of VENUS. And it appears

intervention in quotidian affairs is indeed low, as Marcus claims throughout, then this would provide another avenue for justifying a low prior probability in DIVINE. Notably, however, Marcus does not appear to avail himself of this frequentist strategy; rather, as the above passages show, he rests his case on the dubious theological assumptions that are required by hypotheses like DIVINE.

${ }^{10}$ Since the dice were made from the knucklebones of an animal, the four alternatives were not equi-probable (Wardle 2006: 161-2). 
that he is. As Marcus suggests, it would be foolish to think of Venus as condescending to involve herself in trifling matters such as interfering with the outcomes of dice games.

On my analysis then, part of Marcus' counter-argument depends crucially on assumptions about the nature of the gods, in particular, that they do not intervene in earthly affairs in various ways. Thus, the attempted refutation of Quintus hinges, not on a kind of proto-naturalism or scientific rationalism, but rather on purely theological premises. ${ }^{11}$ Whether Marcus is right about these presuppositions is something I won't attempt to determine. Indeed, one might argue that it's entirely beyond our ken to know what attitudes, goals, and dispositions the gods possess. If this is right, then the prior probability of statements like DIVINE cannot be judged low, but instead must be judged inscrutable. But if the probability of such statements is inscrutable, then it's illegitimate for Marcus to rely on claims like $\operatorname{Pr}($ BEARER $)>\operatorname{Pr}($ DIVINE) in his counter-argument against Quintus. Of course, it would also be illegitimate for Quintus to rely on the opposite claim, i.e. $\operatorname{Pr}($ DIVINE $)>\operatorname{Pr}($ BEARER $)$, which would then leave us at an impasse. It is worth noting that Marcus really does not offer much defense of these crucial theological premises, taking it for granted that the gods would never act in the ways that he regards as undignified. But this means that Marcus' proto-naturalistic critique of divination is held hostage to philosophical theology.

\section{Marcus' Second Skeptical Response: The Causal-Nomological Argument}

We saw in the previous section that two of Marcus' arguments were far from dialectically adequate. There is, however, a third argument against divination that deserves extended attention. I'll call this the "the causal-nomological argument". The interest of this argument consists in the fact that Marcus, despite his earlier criticism, seems to grant Quintus his claims about the reliability of divinatory practices such as astrology or haruspicy. But even with this concession, says Marcus, there is still good reason to reject divination because there is no plausible causal-nomological connection between the signs identified by diviners and the outcomes foretold. There are numerous examples of this argument given by Marcus (e.g. 2.33; 2.34; 2.35-6; 2.36-7; 2.47; 2.142-3). Consider the following:

"Surely if entrails have any prophetic force, necessarily that force either is in accord with the laws of nature, or is fashioned in some way by the will and power of the gods... what possible connexion can there be with-I shall not say the gall of a chicken, whose entrails, some men assert, give very clear indications of the future, but - the liver, heart, and lungs of a sacrificial ox? And what natural quality is there in the entrails which enables them to indicate the future?” (2.29).

\footnotetext{
${ }^{11}$ Here, I come to a similar conclusion as Denyer (1985), who argues that "If [divination] is to be attacked successfully it must therefore be attacked on theological grounds" (p. 9), but for radically different reasons.
} 
According to the causal-nomological argument, even if there is a high correlation between diseased livers in sacrificial animals and disastrous outcomes for the Roman state, we ought not to use haruspicy to predict future outcomes because there is no plausible causal-nomological connection between diseased livers and politico-military missteps. How could diseased livers cause a Roman army to falter? What conceivable law of nature could there be which connects the feeding habits of chickens with Roman victory or defeat? ${ }^{12}$

In Book I, Quintus anticipates this objection, insisting numerous times that all that needs to be true to justifiably practice divination is that the observed associations between sign and signified are sufficiently strong. Quintus is quite clear that causes do not matter:

"I consider that the outcomes of these practices should be investigated rather than their causes" (1.12)

"We see that these signs almost never deceive, but we do not see why this is so" (1.15).

"I do not ask why, since I know what happens" (1.15)

"I am content with this, that, even though I do not know why this happens, I do know what happens" (1.16)

"Likewise, I accept what "the fissure" in entrails means or what "a thread" means; I do not know their cause" (1.16)

On Quintus' view, knowing the causes would be epistemically supererogatory, at least as far as predicting future outcomes is concerned. If it is true that $95 \%$ of the time the diviners are correct, then isn't it rational to employ divination in future instances? Causal understanding might be useful for various reasons, perhaps by helping us to make even more accurate predictions. But, as Quintus claims, such causal-nomological knowledge is not necessary to rationally employ divination, given knowledge of the requisite correlation. Marcus disagrees. Who should we believe?

\subsection{Explicating and Assessing the Ciceronian Causal Requirement (CCR)}

In presenting his third argument against divination, Marcus relies upon a substantive, philosophically interesting claim about proper scientific methodology. Let's call the methodological

\footnotetext{
12 While Marcus in one instance appears to concede the point about causal connections to Quintus (2.34), this is only a temporary assumption that he makes for the sake of point out a further epistemic problem for proponents of divination: how do diviners select the appropriate animal to sacrifice?
} 
claim that underlies the causal-nomological argument the "Ciceronian Causal-Nomological Requirement" (CCR). We can formulate the CCR more precisely as follows:

(CCR) For any two logically distinct event-types $A$ and $B$, it is rational to predict some token-event $b$ of type $B$, on the basis of the presence of some token-event $a$ of type $A$, only if, given one's background knowledge, there is a plausible causal-nomological connection between $A$ and $B{ }^{13}$

According to the CCR, even if the observed associations between events of type $A$ and events of type $B$ is nearly perfect, it is irrational to predict $b$ to be highly probable on the basis of $a$ if there is no plausible causal-nomological connection between $A$ and $B$. To clarify the CCR, it is necessary to say more about what it means for there to be causal-nomological connection between $A$ and $B$.

The most straightforward instance of the requisite sort of connection demanded by the CCR would be if one of the event-types, $A$ and $B$, were the cause of the other. For illustrative purposes, let's suppose that $A$ is "smokes a lot of cigarettes before the age of 50 " and $B$ is "develops lung cancer after the age of 50 ". ${ }^{14}$ Suppose that the probability of developing lung cancer, given that one smokes a lot of cigarettes is .99 , i.e. $\operatorname{Pr}(B \mid A)=.99$, and furthermore, suppose that the prior probability of developing lung cancer is .1, i.e. $\operatorname{Pr}(B)=.1$; such judgments one might defend by appealing to the relevant population frequency data. Given these assumptions, it follows that $\operatorname{Pr}(B \mid A)>\operatorname{Pr}(B)$, which means that there is a probabilistic correlation between $A$ and $B$.

Now then, suppose one wants to know if one should predict whether some randomly selected member of the population who smokes a lot of cigarettes before the age of 50 — call him Gaius-will develop lung cancer after the age of 50. According to the CCR, one is not entitled to infer that Gaius will develop lung cancer unless there is a plausible causal-nomological connection between $A$ and $B$. In this case, clearly there is such a connection. Plausibly, smoking a lot of cigarettes causes lung cancer, in which case the CCR is satisfied.

It's worth noting that this causal connection need not be direct. It's perfectly consistent with the spirit of CCR if $A$ causes some $C$ which causes $B$. In the language of contemporary causal modeling, $A$ need not be a parent of $B$, i.e. a direct cause; it is sufficient if $A$ is an ancestor of $B$, i.e. an indirect cause. Perhaps, smoking cigarettes causes one to engage in some further behavior, which is the more direct cause of lung cancer. Of course, were it possible that $B$ is the cause of $A$, i.e.

\footnotetext{
$13 A$ and $B$ need to be logically distinct to avoid trivial falsity. For example, if $A=$ "is a bachelor" and $B=$ "is an adult, unmarried, male", then, of course, one ought to infer $B$ on the basis of $A$, even though there is no causal connection between $A$ and $B$. The connection between $A$ and $B$ is, instead, logical. Knowledge of this logical connection is what ensures that the inference from $A$ to $B$ is rational.

${ }^{14}$ I borrow this case from Roche and Sober (2013).
} 
developing lung cancer after the age of 50 causes smoking a lot of cigarettes before the age of 50 , then this connection would also work. However, $B$ 's being the cause of $A$ here would violate the prohibition on "backwards causation"-surely, future events cannot cause past events.

Now, $A$ 's being the direct or indirect cause of $B$, or vice versa, are not the only possible ways in which there might be a causal-nomological connection between $A$ and $B$. We should admit at least a third possibility: suppose there is some further event-type $C$, which is the cause of both $A$ and $B$. If there is such a $C$, then there exists a causal connection between $A$ and $B$, but not because $A$ is the cause of $B$, or vice versa, but rather because $A$ and $B$ are the joint effects of some common cause. Let $C$ be the possession of some identifiable genetic profile which predisposes one to be drawn to nicotine and which also makes one highly susceptible to developing lung cancer. In our smoking and cancer case then, $C$ is a cause of both $A$ and $B$, which ultimately accounts for why we observe a correlation between $A$ and $B$, i.e. between smoking and lung cancer.

In our definition of the CCR, I employ the phrase, "there exists a plausible causalnomological connection". This suggests both a strong and a weak reading of the CCR. On the strong reading, one needs sufficient evidence to justify belief in a particular causal explanation. If the strong reading were adopted, then one could infer that Gaius the heavy smoker will develop lung cancer only if one has already established either that smoking causes lung cancer, lung cancer causes smoking, or that some common cause, e.g. a genetic predisposition, brings about both effects. On the weak reading, one doesn't need strong evidence for any particular causal explanation. Instead, some causal story or other connecting $A$ and $B$ must merely be a live option. The weak reading only asks that we come up with some potential causal explanation connecting $A$ and $B$ which fits with our background knowledge, a constraint much easier to satisfy. We might understand this constraint as stating, at bottom, that there must be some causal explanation, given our background knowledge, with a "sufficiently high" prior probability.

There are good textual reasons to attribute something like the weak reading of the CCR to Marcus. For example, in the passage quoted in the previous section, Marcus does not fault Quintus for failing to specify the actual causal explanation for the alleged success of haruspicy; rather, he merely asks "what possible connexion can there be" between entrails and future outcomes (2.29). In other instances, Marcus couches his complaint in similar terms, e.g. "what connexion can there be between the universe and the finding of a treasure?” (2.33), “what natural tie, or what 'symphony,' so to speak, or association...can there be between a cleft in a liver and a petty addition to my purse?" (2.34; emphases mine), etc. Furthermore, it doesn't seem that Marcus demands that the causal connection 
be known with certainty; rather, he makes the weak request of Quintus that the he merely specify some sufficiently plausible causal explanation for the success of divination. As further evidence for the weak reading, consider that Marcus doesn't think that the investigations of Boëthus and Posidonius, both of whom attempted explain various meteorological phenomena, are fruitless, even though Marcus countenances the possibility that "the causes are not discovered by them" (2.47). Presumably, the explanations that Boëthus and Posidonius put forward are plausible enough; and even if those explanations are mistaken, there are likely other live options, thus satisfying the CCR.

Before returning to the debate between Marcus and Quintus, it is worth reflecting on the philosophical adequacy of the CCR. Clearly, the strong reading of the CCR is wildly implausible. The strong reading would severely impoverish our ordinary inductive practice, much of which hinges upon exploiting systematic correlations between $F_{s}$ and $G s$, in the absence of strong evidence for some particular underlying explanation of those correlations. Indeed, the ability to predict, with a high degree of accuracy, certain outcomes of interest simply based on observational data is a hallmark of the so-called "Big Data" movement. According to one Big Data proponent, "[w]e usually don't know about causation, and we often don't necessarily care...the objective is more to predict than it is to understand the world...It just needs to work; prediction trumps explanation" (Siegel 2013: 90). Echoing the words of Quintus (1.15-16), Siegel notes that it's often the case that "[w]e know the what, but we don't know the why," (2013: 90).

While the strong version of the CCR is an untenable constraint on predictive inference, the matter is less clear for the weak version. One reason to adopt the weak version of the CCR is to guard against falling prey to "spurious correlations". Consider the positive correlation between the rise in British bread prices and Venice sea-levels over the past few centuries (Sober 2001). Although there is an observed association between bread prices and sea-levels, it is likely that this strange set of historical trends is a fluke. The British bread prices/Venice sea-levels case is put forward by Sober (2001) as a counterexample to Reichenbach's (1956) Principle of the Common Cause, which states, roughly, that if there is a statistical correlation between $A$ and $B$, then either $A$ caused $B, B$ caused $A$, or $A$ and $B$ are the joint effects of some common cause $C$. However-so the objection goeseven though there is a statistical correlation here, we wouldn't want to posit some detailed and elaborate mechanism to explain the observations, in the sense of providing a common cause to "screen-off" the correlation. We wouldn't want to posit, say, an international conspiracy involving the Illuminati secretly fixing the prices of British bread to match increases in Venetian sea-levels because such an explanation would be highly implausible given our background knowledge. 
Intuitively, we shouldn't use our knowledge of British bread prices in the present year to predict how much Venetian sea-levels will rise, or vice versa. While a correlation has been observed, it is likely that the correlation is merely coincidental. In this case, there is no candidate causalnomological connection between British bread prices and Venetian sea-levels, and so not even the weak version of the CCR is satisfied. Thus, the weak reading of the CCR provides a lucid and attractive account of why we shouldn't exploit such a correlation for predictive purposes.

Indeed, it is along these lines that some epistemologists have objected to the radical claim often made by Big Data enthusiasts that we will soon be able to dispense with theoretical causal models. Our ability to collect large amounts of data has led to deluge of "spurious correlations" (Calude and Longo 2016), those which we shouldn't rely on for prediction. As Pietsch and Wernecke (2017) argue, we should reject the commonly endorsed claim in Big Data circles that causation will prove dispensable for future scientific inquiry. On their view, there's a genuine distinction between those correlations "that can be attributed to a common cause, and then those which have arisen purely by chance", and moreover, "[c]orrelations can establish reliable predictions only in the former case" (Pietsch and Wernecke 2017: 49). Here, I interpret Pietsch and Wernecke (2017) as endorsing something akin to the weak version of the CCR. Those correlations that "can be attributed to a common cause" are ones for which there's a plausible causal-nomological connection given our background knowledge, and those correlations which "have arisen purely by chance" are ones for which there's none. ${ }^{15}$ While I maintain that there are good reasons for the epistemologist to take the CCR seriously, a thorough evaluation of the relationship between causal knowledge and rational predictive inference is beyond the scope of our inquiry. ${ }^{16}$

\subsection{Applying the CCR to the Debate between Marcus and Quintus}

Having said enough to motivate the CCR, we can apply the principle to the debate between Marcus and Quintus. Clearly, the divinatory inferences defended by Quintus don't respect the strong

\footnotetext{
15 Although for simplicity, I've focused on causal connections in explicating the CCR, we should leave open the possibility that there are some nomological (i.e. law-based) connections that are non-causal. For example, it seems right to regard the principle of the constancy of the speed of light as a law of nature, although it is not obvious that this is a causal law. So too, there are well-known difficulties in regarding the laws of quantum mechanics as expressing causal relations (Norton 2003). What matters most, for the purposes of understanding the CCR, is that the correlations at issue are non-accidental/non-coincidental. Such assurances may be afforded by some causal explanation or by some non-causal, yet nomological connection.

${ }^{16}$ For further discussion about issues related to the CCR, it would be profitable to turn to the recent debate between Roche and Sober (2013, 2014, and 2017) and their critics, e.g. McCain and Poston (2014, 2018), Climenhaga (2017), and Lange (2017) over whether "explanatoriness is evidentially irrelevant".
} 
reading of the CCR. But as we've seen, there are good reasons not to attribute the strong reading of the CCR to Marcus. Unfortunately for Marcus, however, it's far from clear that Quintus' main argument runs afoul of the weak version of the CCR. Although Quintus, at the beginning of Book I, is happy to admit his ignorance of the actual causal-nomological connection that allows one to exploit the alleged correlation between diseased entrails and prejudicial future outcomes, he does sometimes gesture at what he takes to be a plausible causal-nomological connection. Even at the beginning of his main argument, Quintus is happy to refer to a "natural force" (1.12), which undergirds our ability to predict future outcomes from present signs.

But the connection to which Quintus most directly appeals is none other than the intentional actions of the gods. Consider the following passages from Book I:

"the gods exist, by their foresight the world is governed, and they are concerned with human affairs, not only in general but also in particular. If we maintain this, which to me seems unassailable, it surely follows that the gods give to men signs of what is to come" (DD, 1.117)

"the world was created from the beginning in such a way that predetermined signs would precede predetermined events, some in entrails, others in birds, others in lightning, others in portents, others in the stars, others in the visions of dreamers, and others in the utterances of those inspired" (1.118)

As an adherent of Stoic school Quintus accepts "the doctrine of divine providential organization of the universe" (Wardle 2006: 390). On the Stoic view, "nothing has happened which was not going to happen and for the same reason nothing will happen the efficient causes of which nature does not contain" (1.125), and moreover, this deterministic system ultimately traces back to the actions of the gods. So, although the gods need not be the direct, proximate cause of any given foretold outcome, since the gods created the whole world system, by setting up the correlations between sign and signified used in divination, the gods act as the ultimate cause undergirding these correlations. Thus, according to Quintus, both diseased entrails and disastrous future outcomes are appropriately connected. They are the joint effects of a common cause: the intentional activity of the gods.

Furthermore, this common cause mechanism is not merely conceivable; rather, Quintus argues, the proposed causal connection is a plausible one. Quintus supports this claim by appealing to a classic line of Stoic reasoning in defense of divination (1.82-84). Since the gods exist, care about human beings, and know about what will happen in the future, and since the gods know that such knowledge would be beneficial to humans, and finally, since communicating with humans is not beneath the dignity of the gods, we can be sure that the gods will indicate important facts about the 
future that bear on human welfare by means of various signs. But all of this is just to say that Quintus believes that those who practice divination respect the weak reading of the CCR.

What response is available to Marcus to the argument that we have made on behalf of Quintus that practitioners of divination do not run afoul of the CCR? It seems that here can only resort to some of the strategies that we saw in section 5. There, Marcus argues that we ought to prefer non-divinatory explanations of the events rather than any divinatory explanation, because the latter, generally, have lower prior probabilities. And the reason that such explanations have lower prior probabilities is that they presuppose that the gods have attitudes, goals, or inclinations that are inconsistent with their divine status. So too here, the only response available to Marcus to save the causal-nomological argument is to insist that the common cause mechanism put forward by Quintus is not, in fact, plausible. And the natural way in which to make this argument is again to object that the gods, by virtue of their divine status, would never condescend to manipulate entrails, the feeding habits of chickens, etc. in order to communicate with humans.

Of course, as before, this defense of the causal-nomological argument depends crucially on contestable theological premises. Although the modern reader is likely sympathetic towards Marcus' theology here, it is far from clear that the causal-nomological argument is dialectically adequate. In the end then, we are led to the same conclusion about the causal-nomological argument as we were led in the case of the strategy of alternative explanations. What looked like a proto-naturalistic or rationalistic critique on the part of Marcus depends, crucially, on a set of contentious claims concerning the attitudes, goals, and abilities of the gods. Ultimately, this makes the critique of divination much more wedded to philosophical or theological assumptions than commentators, both contemporary and historical, have appreciated.

\section{Concluding Remarks}

In the course of my philosophical analysis of the arguments in De Divinatione, several salient themes have emerged. First, as I pointed out, it is important to distinguish two logically distinct argument types employed by Quintus. As I argued, the first type is best regarded as employing enumerative induction, whereas the second type is best regarded as employing IBE. Furthermore, as I have attempted to show, appealing to the probability calculus sheds considerable light on the arguments in the text. My analysis of the counter-arguments of Marcus in Book II reveals that certain purely theological assumptions do a lot more work than it seems at first glance. 
Perhaps the most interesting argument that Marcus makes in response to Quintus is that which appeals to what I have called the "Ciceronian Causal-Nomological Requirement" (CCR), according to which in order to make use of some correlation between $A$ and $B$ for future predictive inference, it is necessary that there be some plausible causal-nomological connection between $A$ and $B$. Either it must be the case that $A$ causes $B$, or that $B$ causes $A$, or that there is some common cause $C$ of which both $A$ and $B$ are joint effects. According to the CCR, unless there is some plausible causal-nomological connection undergirding the correlation, one may not rationally rely on the correlation for predictive purposes, even if the correlation between $A$ and $B$ is nearly perfect.

As I attempted to show, there are good textual and philosophical reasons for attributing the CCR to Marcus. However, as I argued, the application of the CCR in the response to Quintus is far from conclusive. It is the case that Quintus has failed to meet the challenge posed by the CCR only if the common cause mechanism that Quintus defends, which ultimately appeals to the beneficent intentions of the gods, is implausible. But this claim, as before, depends upon contestable theological premises, which it is doubtful that Quintus would accept. The upshot is that Cicero's critique of divination, which has been traditionally regarded as a kind of proto-naturalistic assault on superstition, depends crucially and ironically on assumptions about the nature of the gods.

Even so, it is highly significant that something like the CCR is being actively debated in contemporary epistemology and philosophy of science, especially considering certain radical claims made by proponents of Big Data algorithms. It is to Cicero's credit that he raised issues about the relationship between causal knowledge and predictive inference, and between evidence and explanation, which are of enduring relevance. For this reason, Cicero's oft-neglected De Divinatione deserves a secure place in the history and philosophy of science. 


\section{References}

Beard, M.T. (1986). "Cicero and Divination: The Formation of a Latin Discourse." Journal of Roman Studies 76: 33-46.

Brown, R. (1987). "History versus Hacking on Probability.” History of European Ideas, 8: 655-73.

Calude, C.S. \& Longo, G. (2016). "The Deluge of Spurious Correlations in Big Data”, Foundations of Science, 1-18, doi: 10.1007/s10699-016-9489-4.

Cicero. On Old Age. On Friendship. On Divination. Translated by W. A. Falconer. Loeb Classical Library 154. Cambridge, MA: Harvard University Press, 1923.

Cicero. On the Nature of the Gods. Academics. Translated by H. Rackham. Loeb Classical Library 268. Cambridge, MA: Harvard University Press, 1933.

Climenhaga, N. (2017). "How Explanation Guides Confirmation”, Philosophy of Science, 84: 359-368.

David, F.N. (1969). Games, Gods, and Gambling. London: Griffin.

Denyer, N. (1985). "The Case against Divination: An Examination of Cicero’s De divinatione." Proceedings of the Cambridge Philological Society, 31: 1-10.

Douven, I. (2011). “Abduction”, The Stanford Encyclopedia of Philosophy (Spring 2011 Edition), ed. E. N. Zalta, URL = <http://plato.stanford.edu/archives/spr2011/entries/abduction/>.

Garber, D. and Zabell, S. (1979). "On the emergence of probability." Archive for History of Exact Sciences, 21(1): 33-53.

Hacking, I. (1975). The Emergence of Probability: A Philosophical Study of Early Ideas about Probability, Induction and Statistical Inference. Cambridge University Press.

Harman, G. (1965). “The Inference to the Best Explanation,” Philosophical Review, 74: 88-95.

Jeffrey R. (1984). “De Finetti's probabilism.” Synthese, 60: 73-90.

Krostenko, B.A. (2000). “Beyond (Dis)belief: Rhetorical Form and Religious Symbol in Cicero's De divinatione." Transactions of the American Philological Association 130: 353-91.

Lange, M. (2017). “The Evidential Relevance of Explanatoriness: A Reply to Roche and Sober.” Analysis, DOI: 10.1093/analys/anx045.

Laudan, L. (1978). "Ex-huming Hacking." Erkenntnis, 13(1): 417-435.

Lehoux, D. (2012). What Did the Romans Know?: An Inquiry into Science and Worldmaking. University of Chicago Press.

Linderski, J. (1982). "Cicero and Roman divination.” Par. Pass., 37: 12-38.

Lipton, P. (2004). Inference to the Best Explanation, $2^{\text {nd }}$ ed. New York: Routledge.

Lycan, W.G. (1988). Judgement and justification. Cambridge: Cambridge University Press. 
McCain, K. \& Poston, T. (2014). "Why Explanatoriness is Evidentially Relevant," Thought 3: 145-53.

McCain, K., \& Poston, T. (2018). “The Evidential Impact of Explanatory Considerations”, in McCain and Poston (eds.), Best Explanations: New Essays on Inference to the Best Explanation. Oxford: Oxford University Press, 121-29.

Norton, J.D. “Causation as Folk Science,” Philosophers' Imprint, 3(4): 1-22.

Okasha, S. (2000). "Van Fraassen's Critique of Inference to the Best Explanation," Studies in the History and Philosophy of Science, 31: 691-710.

Pease, A.S. (1920). M Tulli Ciceronis. De Divinatione. Urbana: University of Illinois.

Pietsch W. \& Wernecke J. (2017). “Introduction: Ten Theses on Big Data and Computability,” In: Pietsch W., Wernecke J., Ott M.(eds.), Berechenbarkeit der Welt?. Springer VS, Wiesbaden.

Poston, T. (2014). Reason \& Explanation: A Defense of Explanatory Coherentism. New York: PalgraveMacMillan.

Psillos, S. (2002). "Simply the Best: A Case for Abduction," in A. C. Kakas and F. Sadri (eds.), Computational Logic: Logic Programming and Beyond. Berlin: Springer-Verlag, 605-26.

Reichenbach, H. (1956). The Direction of Time. Berkeley: University of California Press.

Roche, W. \& Sober, E. (2013). "Explanatoriness is evidentially irrelevant, or inference to the best explanation meets Bayesian confirmation theory," Analysis, 73: 659-668.

Roche, W. \& Sober, E. (2014). "Explanatoriness and Evidence: A Reply to McCain and Poston," Thought, 3(3):193-199.

Roche, W. \& Sober, E. (2017). "Is explanatoriness a guide to confirmation? A reply to Climenhaga," Journal for General Philosophy of Science, 48(4): 581-590.

Siegel, E. (2013). Predictive Analytics: The Power to Predict Who Will Click, Buy, Lie, or Die. Hoboken: Wiley.

Sober, E. (2001). "Venetian Sea Levels, British Bread Prices, and the Principle of the Common Cause," Brit. J. Phil. Sci., 52(2):331-346.

Thagard, P. (1978). The Best Explanation: Criteria for Theory Choice," The Journal of Philosophy, 75(2): 76-92.

Wardle, D. (ed., trans.) (2006). Cicero: On Divination Book 1. Oxford: Clarendon Press.

Weisberg, J. (2009). "Locating IBE in the Bayesian Framework." Synthese, 167: 125-43.

Woolf, R. (2015). Cicero: The Philosophy of a Roman Sceptic. Routledge. 